\title{
Laparoscopic Gastric Banding Outcomes Do Not Depend on Device or Technique. Long-Term Results of a Prospective Randomized Study Comparing the Lapband ${ }^{\circledR}$ and the SAGB ${ }^{\circledR}$
}

\author{
Daniel Gero • Anna Dayer-Jankechova • \\ Marc Worreth • Vittorio Giusti • Michel Suter
}

Published online: 26 September 2013

(C) Springer Science+Business Media New York 2013

\begin{abstract}
Background Gastric banding still represents one of the most widely used bariatric procedures. It provides acceptable weight loss in many patients, but has frequent longterm complications. Because different types of bands may lead to different results, we designed a randomized study to compare the Lapband ${ }^{\circledR}$ with the SAGB ${ }^{\circledR}$. We hereby report on the long-term results.

Methods Between December 1998 and June 2002, 180 morbidly obese patients were randomized between Lapband ${ }^{\circledR}$ or SAGB $^{\circledR}$. Weight loss, long-term morbidity, and need for reoperation were evaluated.

Results Long-term weight loss did not differ between the two bands. Patients who maintained their band had an acceptable long-term weight loss of between 50 and $60 \%$ EBMIL. In both groups, about half the patients developed long-term complications, with about $50 \%$ requiring major redo surgery. There was no difference in the overall rates of long-term complications or failures between the two groups, but patients who had a Lapband ${ }^{\circledR}$ were significantly more prone to develop band slippage/pouch dilatation ( 13.3 versus $0 \%, p<0,001)$.

Conclusions Although in the absence of complication, gastric banding leads to acceptable weight loss; the long-term
\end{abstract}

D. Gero $\cdot$ M. Suter $(\bowtie)$

Department of Surgery, Hôpital du Chablais,

1860 Aigle-Monthey, Switzerland

e-mail: michelsuter@netplus.ch

A. Dayer-Jankechova $\cdot$ M. Suter

Department of Visceral Surgery, CHUV, Lausanne, Switzerland

M. Worreth

Department of Surgery, Hôpital du Jura, Delémont, Switzerland

V. Giusti

Division of Endocrinology, Diabetology and Metabolism, CHUV,

Lausanne, Switzerland complication and major reoperation rates are very high independently from the type of band used or on the operative technique. Gastric banding leads to relatively poor overall long-term results and therefore should not be considered the procedure of choice for the treatment of morbid obesity. Patients should be informed of the limited overall weight loss and the very high complication rates.

Keywords Bariatric surgery · Gastric banding · Obesity · Complications

\section{Introduction}

Obesity, and especially morbid obesity, has become a widespread phenomenon in most western countries. Epidemiologic studies show an amplification of the current trends with a prediction of obesity prevalence reaching $30 \%$ among European adults in 2015 similar to the situation in the USA nowadays. Severe obesity-associated comorbidities lead to impaired overall health status, reduced quality of life, and higher mortality, especially from cardiovascular causes and cancer. In the absence of efficient medical therapies, bariatric surgery remains the form of treatment that is both efficient and durable. Before the laparoscopic era, bariatric surgery was regarded by many patients and physicians as a dangerous tool associated with a relatively high risk of complications. Most bariatric procedures are currently performed by laparoscopy, which has largely contributed to a reduction in surgery-related morbidity and mortality. As a consequence, we currently face a rapidly increasing demand for bariatric surgery both from patients and their doctors.

Gastric banding (GB) was the first laparoscopic bariatric procedure $[1,2]$. Its early surgical morbidity and mortality were rapidly shown to be minimal, especially when compared to those of open bariatric procedures like vertical 
banded gastroplasty, the operation most commonly performed in Europe at the time of its introduction [3]. This lead to a rapid gain of its popularity during the mid 1990s. After very enthusiastic initial results, however, it became apparent that sufficient weight loss could not always be achieved and that long-term complications arose after some time in a significant proportion of the patients, leading to band deflation with weight regain or reoperations [4-7]. To reduce the rate of pouch dilatation and slippages, one of the most common complications in the early days, the surgical technique was modified with the introduction of the pars flaccida technique. Bands were also improved in both their construction and design, and protocols for patient follow-up and band adjustment were developed using not only weight loss as a base for band adjustment but also other factors such as food tolerance, hunger, and satiety. Except for one study that showed a lower posterior pouch dilatation rate with the new technique [8], the literature is still lacking hard data showing if all these modifications have resulted in significant improvement of the results.

In 1998, when GB was still and by far our procedure of choice to treat morbid obesity, we designed a prospective randomized trial with the intention to compare the results of the two bands that were available at the time, the Lapband ${ }^{\circledR}$ (Bioenterics, Carpinteria, California, USA, now Allergan) and the Swedish Adjustable Gastric Band (SAGB $\left.{ }^{\circledR}\right)$ (Obtech Medical, Zug, now Ethicon Endosurgery). Our hypothesis at this time was that the softer band (SAGB), which had a larger balloon, would result in better food tolerance, allow for finer band adjustments, and perhaps result in better weight loss. Our early results, reported in 2005 [9], failed to show any significant difference between the two bands up to the 3-year term, both in terms of weight loss as of complications. All patients have now been followed for at least 10 years, with an average of 12 years. In this paper, we now report on long-term results of this study.

\section{Patients and Methods}

Patients and Randomization

Participation in this study was proposed between December 1998 and June 2002 to all patients scheduled for laparoscopic gastric banding. All patient were fully evaluated by a multidisciplinary team specialized in the management of morbid obesity. They also underwent preoperative upper gastrointestinal endoscopy and echography. Most patients were also submitted to $24 \mathrm{~h}$ baseline $\mathrm{pH}$ monitoring and esophageal manometry. Exclusion criteria were severe reflux disease, large hiatus hernia $(>2 \mathrm{~cm})$, redo bariatric surgery, and patient's refusal and contraindications to laparoscopy. Patients with a large hiatus hernia $(>2 \mathrm{~cm})$ or severe reflux were offered Roux-en-Y gastric bypass. The protocol was accepted by the local ethics committee on November 9, 1998. Informed consent was obtained from all patients. Randomization was done using numbered sealed envelopes, which were opened immediately before surgery. To facilitate interim analysis, the envelopes were grouped so that there would be an equal number of patients in each study arm after every ten patients.

\section{Primary and Secondary Endpoints}

The primary endpoint was weight loss as this is the first goal of any bariatric procedure. Secondary endpoints were early and late complications, reoperations, the proportion of patients with an excess BMI loss (EBMIL) of at least $50 \%$ (success rate in terms of weight loss), and the overall failure rate (EBMIL $<25 \%$ or band removal \pm conversion to another bariatric procedure). Power calculations suggested that at least 81 patients would be needed in each group to identify a $10 \%$ difference in the percentage of EBMIL, with a power of $80 \%$ at the $5 \%$ significance level. With the same power and significance levels, it was also calculated that at least 307 patients would be required in each group to identify a $50 \%$ reduction in the long-term complication rates (from $16 \%$ as observed during our early experience (excluding the learning curve) to $8 \%$ ).

\section{Operative Procedures}

We had performed a total of $144 \mathrm{~GB}$ before we initiated this study, 98 with the Lapband ${ }^{\circledR}$, and 46 with the $\mathrm{SAGB}^{\circledR}$ so that the learning curve was therefore behind us. The same surgeon performed himself or participated in all the procedures. Prophylactic antibiotics (amoxicillin clavulanate $2.2 \mathrm{~g}$ or cefuroxim $1.5 \mathrm{~g}$ ) were administered as a single dose at the induction of anesthesia. Thromboembolic prophylaxis was provided using low molecular weight heparin which started at the induction of anesthesia and was maintained until the end of the fourth postoperative week.

The surgical technique has been described in details elsewhere [5]. The Lapband ${ }^{\circledR}$ was placed using the perigastric technique, which was still the prevailing technique when the study began in 1998 , and the $\mathrm{SAGB}^{\circledR}{ }^{\circledR}$ was placed according to the pars flaccida technique. In all cases, care was taken to place the band above the lesser omental sac. When using the perigastric technique, if the lesser sac was entered during dissection, a new retrogastric tunnel was created higher up. All bands were secured anteriorly with four gastro-gastric sutures. The band was left empty at the end of the procedure.

\section{Postoperative Care}

The patients followed a semiliquid diet for the first postoperative month, after which a barium swallow was performed to 
assess the position of the band. The first band inflation was usually done at this time. The patients were then instructed to follow a well-balanced solid diet, to take small bites, to chew well, to eat slowly, to avoid drinking while eating, and to avoid sparkling drinks. Further, band adjustments were performed as necessary during follow-up, depending on the patient's weight loss, eating capacities, sensation of hunger and satiety, and sometimes radiological and/or endoscopic appearance. The maximal capacity of the band $(5 \mathrm{ml}$ for the Lapband ${ }^{\circledR}$ and $9 \mathrm{ml}$ for the $\mathrm{SAGB}^{\circledR}$ ) was strictly respected. Patients were seen every month for the first semester, every 2 months during the second semester, quarterly the second year, biannually up to 5 years, and at least yearly thereafter. Barium swallows were routinely repeated after $12-18$ months, after 3 years, and then every 2 years or if mandated by an abnormal clinical course. Gastroscopy was used liberally in patients with symptoms suggesting a possible problem.

Long-term complications were divided into two categories. Major complications were either life-threatening or lead to band removal, while minor complications included revisions maintaining the band in place. Patients whose band had to be removed and/or who were converted to another bariatric procedure were excluded from further weight loss analysis. However, for the purpose of an intention-to-treat analysis, they remained included in the analysis regarding the percentage of patients achieving an EBMIL of at least $50 \%$ in which they were considered as failures as of the time of band removal or conversion.

\section{Evaluation of Results}

The percentage of EBMIL and the body mass index (BMI) were used to evaluate weight loss [10]. As a BMI of 25 represents the upper limit for normal weight, this was considered as corresponding to the ideal weight. Excess BMI was the difference between the actual BMI and 25. The percentage of patients reaching an EBMIL of at least $50 \%$ (therapeutic success) was also calculated. Failure was defined as an EBMIL $<25 \%$ or the need for band removal/conversion. Showing weight loss results only in patients who retain their band, however, gives a wrong impression of the overall results. In order to depict the latter in a more realistic way, a separate "intention-to-treat" analysis was performed with the evolution of BMI over time. In the latter, the initial BMI was carried forward as of the time of reoperation in patients who required band removal.

\section{Statistical Analysis}

Comparisons between groups were made using the Student's $t$ test or the Mann-Whitney $U$ test for continuous variables. The Chi-square test with Yates correction, if necessary, or the Fisher's exact test were used for categorical variables as appropriate. Differences were considered significant with $p \leq 0.05$.

\section{Results}

One hundred eighty patients of 181 eligible patients were included in the study between December 1998 and June 2002 at which time patient recruitment was stopped (see flow chart, Fig. 1). At that time, laparoscopic Roux-en-Y gastric bypass had largely replaced gastric banding as the primary bariatric procedure of choice at our institution. A single patient refused to participate. The preoperative characteristics did not differ between groups, except for age, which was 3 years older in the Lapband ${ }^{\circledR}$ group (Table 1). All patients received the allocated intervention. Ninety patients in group A received a Lapband ${ }^{\circledR}$, and 90 patients in group $\mathrm{B}$ received a $\mathrm{SAGB}^{\circledR}$. Early results, including early morbidity, have been published previously [1] and this report focuses only on long-term results.

The mean duration of follow-up was 144 months. At the time of analysis, four patients had died from causes unrelated to obesity or to the procedure. All the remaining patients had a follow-up of at least 10 years, with 166 $(94.3 \%)$ available for analysis at this term. There was no significant difference in follow-up rates between the two groups. One hundred eight $(92.3 \%)$ out of 117 eligible patients were available at 12 years.

The two groups had very similar results in terms of weight loss. Figure 2 depicts the results in terms of EBMIL, and Fig. 3 shows the evolution of the mean BMI. Patient who still had their band in place maintained an average EBMIL of 50-60\% throughout the study period. Weight loss was faster in group A than in group B, but the difference disappeared after 2 years. In order to provide a perspective of the overall results regarding weight loss, taking into account the fact that band removal is in

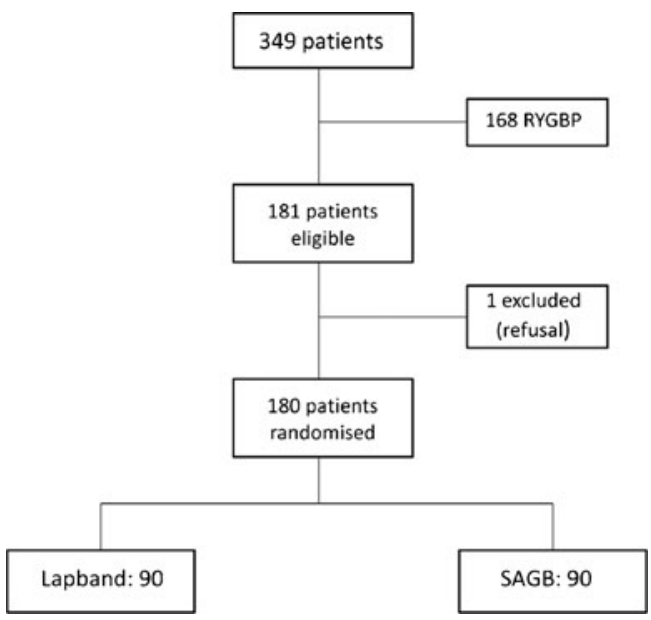

Fig. 1 Flow chart of patient accrual during the study period (RYGBP Roux-en-Y gastric bypass) 
Table 1 Preoperative patient's characteristics

\begin{tabular}{lccc}
\hline & Lapband (A) & SAGB (B) & $p$ value \\
\hline Weight (extremes) & $116.1 \mathrm{~kg}(79.4-161)$ & $119.9 \mathrm{~kg}(87.5-165)$ & 0.11 \\
BMI (extremes) & $42.6 \mathrm{~kg} / \mathrm{m}^{2}(34.4-55.6)$ & $43.4 \mathrm{~kg} / \mathrm{m}^{2}(34.3-51.6)$ & 0.18 \\
Excess weight & $92.5 \%(54-155)$ & $97.3(52-137)$ & 0.17 \\
Age & 39.5 years $(22-64)$ & 36.3 years $(19-62)$ & 0.03 \\
Comorbidities & $82.2 \%$ & $84.4 \%$ & $\mathrm{NS}$ \\
\hline
\end{tabular}

most cases associated with progressive weight regain unless another procedure is performed, we also calculated the mean BMI at each term in an "intention-to-treat" analysis, where the initial BMI was carried forward as of the time of reoperation in patients who required band removal (Fig. 4).

Long-term complications were very common in both groups and continued to develop over time (Table 2). There was a significant difference between the two groups with respect to pouch dilatation \pm slippage, which developed in $13 \%$ of the patients after Lapband ${ }^{\circledR}$ compared with none in the SAGB group $(p<0.001)$. The incidences of all other individual complications were similar between groups, and there was no difference in the overall incidence of longterm complications. Major long-term complications leading to band removal were common, with a 50 and $48.9 \%$, respectively, after Lapband and SAGB.

A high number of reoperations were required during the follow-up period. Most band- or port-related minor complications were corrected under local anesthesia (port/tubing problems). Many patients eventually required band removal, with or without conversion to another bariatric procedure (Table 3).

The total failure rate (Fig. 5), defined as either the need for major reoperations or failure to achieve sufficient weight loss (EBMIL $<25 \%$ ), increased over time in both groups with rates between 50 and $60 \%$ after 10 years. The total failure rate was higher at all time points in group B, with a significant difference up to 4 years. This was due in part to faster weight loss in group $\mathrm{A}$ in part to a higher incidence of major complications

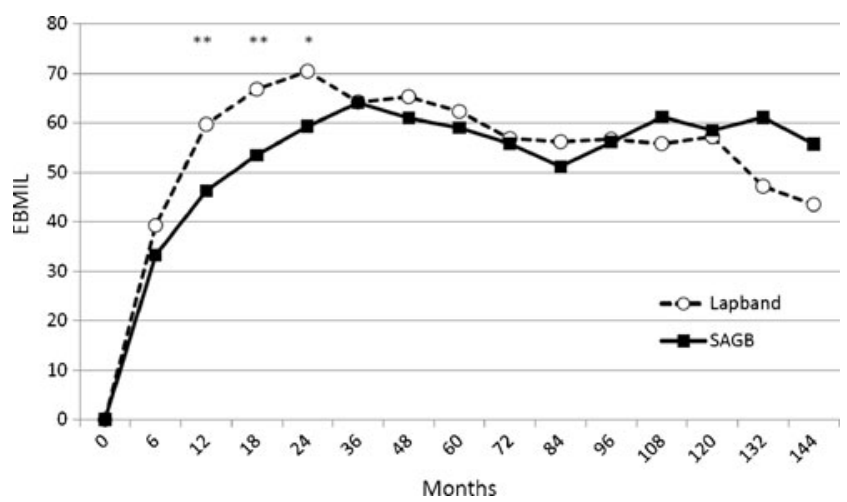

Fig. 2 Excess BMI loss $(E B M I L)$ : comparison between Lapband ${ }^{\circledR}$ and $\mathrm{SAGB}^{\circledR}$. $* p<0.05 ; * * p<0.001$ during early follow-up in group B. The difference, however, lost statistical significance as of the fifth postoperative year.

\section{Discussion}

The long-term follow-up results of this randomized trial showed that (a) long-term weight loss is similar with the Lapband ${ }^{\circledR}$ or the $\mathrm{SAGB}^{\circledR}$ in patient who retain their band, (b) both bands are associated with high long-term complication and reoperation rates, and (c) GB with either band has a high long-term failure rate.

GB is a short and relatively simple laparoscopic procedure which preserves the digestive tract. It has low perioperative morbidity and almost no mortality. It can be performed on an outpatient basis, in many cases, is adjustable and reversible. As such, GB could be perceived as the ideal operation for high-risk morbidly obese patients. It works essentially as a purely restrictive procedure even though some authors recently theorized that it did not provide true restriction (the passage of food is not slowed down) but instead a rapid sensation of satiety, possibly mediated by the vagus nerve, caused by the esophagus squeezing food through the band [11].

Since the introduction of laparoscopic adjustable GB, two main bands, with their subsequent modifications, have been used: the Lapband ${ }^{\circledR}$ and the SAGB ${ }^{\circledR}$, with their subsequent modifications. Several other models are currently available on the market, although not approved in every

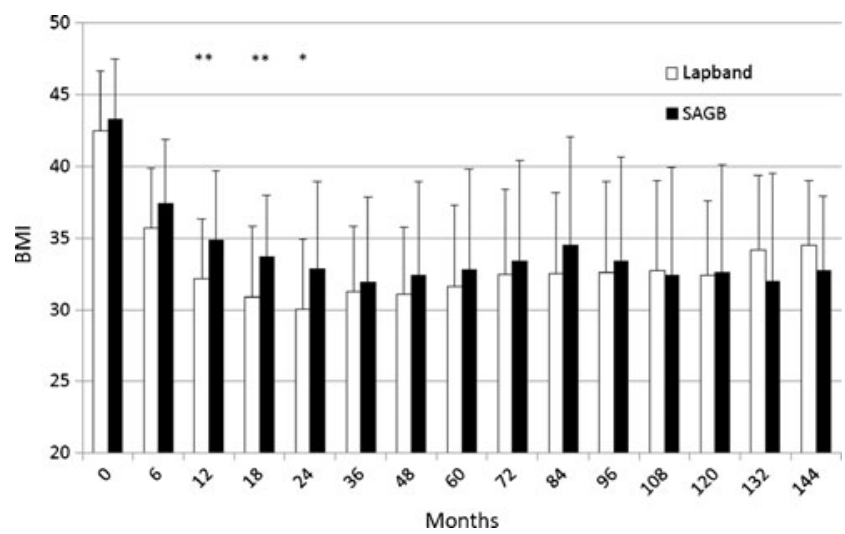

Fig. 3 Evolution of BMI with SD. Comparison between Lapband ${ }^{\circledR}$ and $\mathrm{SAGB}^{\circledR} .{ }^{*} p<0.05 ; * * p<0.01$ 


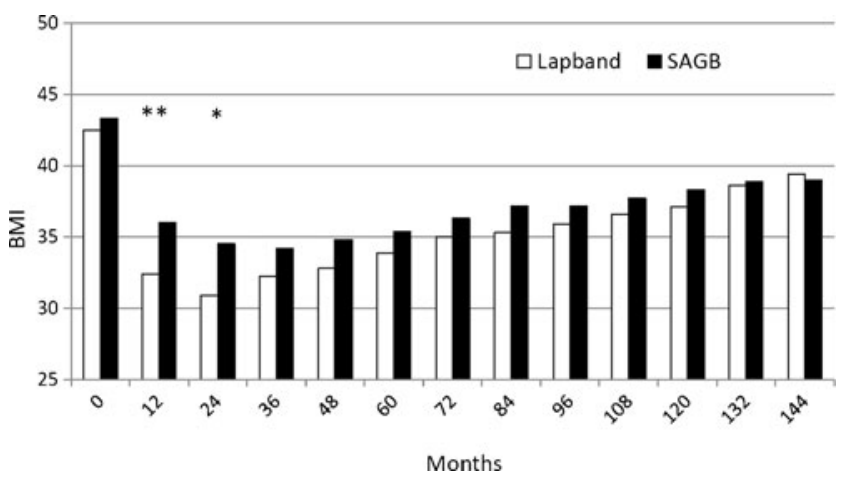

Fig. 4 Evolution of BMI in an "intention-to-treat" analysis. Comparison between Lapband ${ }^{\circledR}$ and $\mathrm{SAGB}^{\circledR}$. ** $p<0.001 ; * p<0.01$

country. The Lapband ${ }^{\circledR}$ that was used in this study is a rigid and relatively narrow $(12.5 \mathrm{~mm})$ silicone band with an inner balloon that can be inflated up to $5 \mathrm{ml}$ according to the manufacturer. It is described as a high-pressure band since the pressure created within the balloon rapidly increases to values well above $150 \mathrm{kPa}$ [7]. The $\mathrm{SAGB}^{\circledR}$ is a soft silicone band that is much wider $(23 \mathrm{~mm})$ with a balloon that can be inflated up to $9 \mathrm{ml}$ and is described as a low pressure system since the inner pressure of the balloon remains relatively low even with maximal inflation. Some of the differences between these two bands could theoretically account for differences in results. The greater volume of the SAGB ${ }^{\circledR}$ could make fine adjustment easier, with low pressure on the gastric wall, thereby providing better food tolerance, reduced vomiting/regurgitation, and possibly increase weight loss. Its wide design could reduce the pressure transmitted to the gastric wall, resulting in fewer erosions, and also help avoiding band slippage. On the other hand, the Lapband ${ }^{\circledR}$ with its smooth and narrow inner surface could increase the risk of erosion and slippage. To the best of our knowledge, the present study is the first randomized trial comparing these two devices and providing long-term ( $>10$ year) results.

Patients who retained their band maintained on average an EBMIL of between 50 and $60 \%$, which is considered acceptable according to bariatric standards and compares well to long-term results of other procedures such as Rouxen-Y gastric bypass [12, 13]. Unfortunately, and sometimes only several years after surgery, many patients eventually developed long-term complications. This often leads to band deflation in an attempt to reduce side effects (poor food tolerance, heartburn, regurgitation, and pulmonary symptoms) or directly to band removal (erosion or infection). The problem is that the majority of patients in whom the band needs to be deflated regain weight progressively despite further education or dietary counseling. Most of them eventually ask for a tighter band adjustment again. Our policy in these cases is to re-inflate the band very slowly and by very small increments to prevent recurrence of side effects/complications, with radiological and/or endoscopic surveillance if necessary notably to assess reversal of esophageal dilatation/dysmotility or esophagitis. Experience, however, shows that complications or side effects tend to slowly return over time with a tighter band, leading to patient's dissatisfaction despite renewed weight loss. In the majority of cases, a time comes when we have to discuss with the patient between accepting insufficient weight loss with adequate quality of life and minimal side effects or aiming for better weight loss with conversion to another procedure, which represents a failure for the band in terms of intention-to-treat. While success, which should be defined as a combination of acceptable weight loss, resolution/improvement of comorbidities and improvement of quality of life, is often achieved in the absence of complication, this high long-term complication rate is of great concern, with a 50-60\% 10-year failure rate in this study.

Morbid obesity is a chronic and evolving disease, for which one single surgical intervention is unlikely to provide definitive relief in all the patients. Each surgical procedure, however, places the patient at risk for complications. We agree that the risks of a port revision under local anesthesia are minimal, but those of laparoscopic band repositioning or replacement under general anesthesia are certainly higher, with a non-negligible risk of further complication leading to further revisional surgery. Conversion
Table 2 Long-term complications

GERD gastroesophageal reflux disease

\begin{tabular}{llll}
\hline Type of complication & Lapband & SAGB & $p$ value \\
\hline Pouch dilatation/slippage & $13(14.4 \%)$ & $0(0 \%)$ & $<0.001$ \\
Band erosion & $9(10 \%)$ & $11(12.2 \%)$ & 0.81 \\
Severe GERD/late food intolerance & $17(18.9 \%)$ & $18(20 \%)$ & 1.0 \\
Esophageal dilatation/dysmotility & $20(22.2 \%)$ & $10(11.1 \%)$ & 0.07 \\
Port/tube complications & $10(11.1 \%)$ & $8(8.9 \%)$ & 0.80 \\
Others & $1(1.1 \%)$ & $9(10 \%)$ & 0.18 \\
Total patients with complication(s) & $54(60 \%)$ & $50(55.5 \%)$ & 1.0 \\
Total patients with reoperation & $51(56.7 \%)$ & $47(52.2 \%)$ & 0.65 \\
Total patients with major reoperation & $45(50 \%)$ & $44(48.9 \%)$ & 0.99 \\
\hline
\end{tabular}


Table 3 Long-term reoperations

\begin{tabular}{llll}
\hline Type of reoperation & Lapband (A) & SAGB (B) & $p$ value \\
\hline Tube/port procedure & $10(11.1 \%)$ & $9(10 \%)$ & 0.99 \\
Isolated band removal & $10(11.1 \%)$ & $11(12.2 \%)$ & 0.99 \\
Band change & $1(1.1 \%)$ & $0(0 \%)$ & 1 \\
Conversion to RYGBP & $35(38.9 \%)$ & $32(35.5 \%)$ & 0.75 \\
Total patients with reoperation & $51(56.7 \%)$ & $47(52.2 \%)$ & 0.65 \\
Total patients with major reoperation & $45(50 \%)$ & $44(48.9 \%)$ & 0.99 \\
\hline
\end{tabular}

$R Y G B P$ Roux-en-Y gastric bypass term follow-up rate was very low (29\% at 5 years), preventing meaningful conclusion [23].

GB has been an evolving operation, but its basic principle - providing adjustable food restriction by an adjustable band place around the proximal stomach - has remained the same since almost 20 years. The technique of band implantation has shifted from the originally described perigastric technique to the now widely (but not yet uniformly) accepted pars flaccida technique. The device itself has evolved over time. The Lapband ${ }^{\circledR}$ and the SAGB ${ }^{\circledR}$ that were used in this study more than 10 years ago are no longer available and have now been replaced by newer devices. Some of the advantages of the modifications seen during the past decade have clearly been demonstrated like a marked reduction in the posterior pouch dilatation/slippage rates with the pars flaccida technique [8]. Symmetrical pouch dilatation, however, remains a problem [24], and a recently published report from Australia showed similar overall long-term complication rates between patients operated with the perigastric or the pars flaccida technique [11]. Other potential benefits of the newer devices will require long-term surveillance before definitive conclusions can be drawn.

Like for many other bariatric procedures, there is a paucity of reports on long-term results after GB. Series with $\geq 5$-year results are scarce and those with $\geq 10$ years are exceptional. O'Brien et al. recently published long-term results up to 16 years in their cohort of 3,227 patients operated between 1993 and 2011 [11]. The long-term EBMIL was around $47 \%$ beyond the 10 -year term, which is clearly less than the $66 \%$ reported by Higa et al. [13] or the $62 \%$ observed currently by ourselves (unpublished data) 10 years after Roux-en-Y gastric bypass (RYGBP). An impressive number of patients required revisional surgery even among those operated with the pars flaccida technique. The need for revision decreased during the most recent period, but the mean duration of follow-up does not exceed 3 years, which makes comparison difficult. Another series with long-term results has been published by Himpens et al. [25], who reported on a group of 151 with a follow-up rate of $54 \%$ after 12 years. The mean excess weight loss (EWL) in the 70 available patients was $42.8 \%$, but differed markedly between patients who retained their band (48\%), those in whom the band was removed (23\%),
Fig. 5 Failure rate over time, combining patients who required band removal with those who did not achieve an EBMIL of $25 \%$. $* * p<0.01 ; * p<0.05$ 
and those who underwent conversion to RYGBP (64\%). Close to $60 \%$ of patients required at least one reoperation, and band removal was necessary in $50 \%$ of the case, a figure very similar to ours. The authors concluded that GB appeared to result in relatively poor long-term outcomes. Another recent report from Belgium described outcomes with the SAGB implanted using the pars flaccida technique [26]. In 745 patients, with a follow-up rate of $88 \%$ after 8 years, the mean EWL was $46 \%$. A total of 319 reinterventions were necessary in 234 patients ( $31.4 \%$ ), and $24 \%$ of the patients had their band removed after a mean of 7 years. For the authors, this high reoperation rate did not allow supporting GB as the firstline surgical option for morbid obesity. Lanthaler et al. also recently published their long-term results in a series of 276 patients with a follow-up of at least 9 years and considered their results as disappointing [27]. One hundred forty-six patients (53\%) developed a total of 190 complications requiring 220 reoperations. At the end of the study period, only 148 patients $(53.6 \%)$ still had their original band in place and another $49(17.8 \%)$ had their band changed at some time, with acceptable EWL after 10 years. The remaining 79 patients (28.6\%) no longer had a band. We have previously published our results in a group of 317 patients with a mean follow-up of 74 months: EWL between 50 and $60 \%$ up to 7 years after surgery in patients who retain their band, success rate (EWL $\geq 50 \%$ ) of $43 \%$ and failure rate (EWL $<25 \%$ or band removal) of $37 \%$ after 7 years [28]. Balsiger et al., with a major 7-year complication rate of $32 \%$ in a group of 196 patients, concluded that procedures other than GB, mainly Roux-en-Y gastric bypass, should be discussed and offered to the patients [29]. In a series of 199 patients, Boza et al. found a $33.6 \%$ long-term complication rate and a failure rate (EWL $<50 \%$ ) of $46.3 \%$ at 5 years. They have abandoned the use of GB in their bariatric armamentarium [14].

Others are more optimistic and still consider GB as an acceptable first-line procedure for morbidly obese patients despite high long-term complication and failure rates [11, 30-32]. Many stress the importance of very close patient follow-up and education, some even introducing the notion of partnership between the patient and the bariatric team. Some authors attempt to select patients on the basis of preoperative factors, such as anatomic and functional studies of the upper GI tract [11, 33-37], age/sex/BMI of the patients, or their willingness to durably modify their eating habits and their lifestyle [38]. All published series of GB for morbid obesity include a cohort of patients, variable in size, with excellent results both in terms of weight loss, and overall quality of life. These few patients do not develop complications up to 15 years after surgery. This is also our experience, but as the years pass, the proportion of patients in this group diminishes considerably, and it represents a minority of the whole series of patients beyond the 10-year limit, with no significant difference between two bands evaluated in this study (17 versus 16 patients with $\mathrm{BMI}<30$ and no long-term complication 10 years after implantation, $p=\mathrm{NS}$ ). All bariatric operations can be followed by long-term complications, sometimes even reoperations, but the need for reversal or conversion to another operation varies between procedures. It is exceptional after RYGBP, as opposed to GB. Several comparative studies, in fact, have concluded that RYGBP is superior to GB in the long term, both in terms of weight loss, morbidity, and the need for reoperations [39-43].

One of the problems that many GB patients experience is the limited food tolerance, which tends to worsen over time. This is very unusual with other bariatric procedures and notably after Roux-en-Y gastric bypass. When we planned this randomized trial, one of our hypothesis was that a softer band, the $\mathrm{SAGB}^{\circledR}$, would lead to better food tolerance than a hard one like the Lapband ${ }^{\circledR}$. We have previously shown that there was no difference in food tolerance at any time point up to 6 years after surgery between the two bands [44].

One strength of our study is the long duration of follow-up, which averages 144 months, together with a follow-up rate exceeding $90 \%$ after 10 years. Also, all patients were evaluated and followed up by a multidisciplinary group, including specialized dieticians and psychologists, with very regular follow-up for most patients. Complications, especially those potentially leading to intra-abdominal revision under general anesthesia, were first treated conservatively if possible, with the decision to re-operate made only after failure of initial therapy and/or persistence of symptoms/weight regain.

On the other hand, this study has a number of limitations. First, the bands that were used are not available anymore. Secondly, our study compares two bands implanted with two different techniques (perigastric and pars flaccida), which might introduce a bias in the results. Nonetheless, the fact that no significant difference was found between the two devices in terms of long-term weight loss or overall complication and reoperation rates prompts us to conclude that results of GB are very likely more related to its general concept than to the implanted device or the surgical technique. In fact, comparing two bands implanted with two different techniques might also be considered a strength in this study. Third, our study was not powered initially to detect differences in long-term complications or failure rates. A post hoc analysis, however, showed that 93 patients were needed in each group to detect a $40 \%$ reduction in long-term major morbidity. Finally, our cohort includes largely unselected patients, as most series reporting on long-term results of GB.

Proponents of GB currently claim that better patient selection, better devices, better surgical technique, together with improved patient education and aftercare will lead to improved long-term results with GB. They have failed, so far, to provide us with convincing long-term results. In the present series, only patients with a large hiatus hernia \pm severe reflux disease were not offered GB. It is now generally accepted that not every 
patient can adhere to severe food restriction as the one desirable following gastric banding. Some tend to overeat and vomit/ regurgitate frequently, while others progressively switch to a soft semiliquid high-energy diet, both leading to complications and/or poor weight loss/weight regain. Poor adaptation can be related to the patient (culture, education, and inability to chew due to dental problems) or to the environment (social and professional life, time allotted to a meal, etc.). We and others have shown that some pre-existing conditions, like gastrooesophageal reflux or oesophageal motility disorders, especially low lower oesophageal sphincter pressure, could be associated with poorer outcome [34-37]. Criteria which could help ruling out patients with known preoperative risk factors would indeed be very helpful to reduce the high long-term complication rates after GB. Many groups are currently trying to select patients, but several years will be required before we know whether this attitude, together with the use of newer devices, has a real impact on the long-term overall results.

\section{Conclusions}

This randomized controlled trial comparing two different gastric bands inserted with two different surgical methods for unselected morbidly obese patients shows no significant difference in the overall long-term results. We conclude that, except for posterior slippage, which is seen almost exclusively with the now outdated perigastric technique, long-term outcome of GB is more likely to be related to the concept of the procedure itself than to the type of band or surgical technique. In unselected morbidly obese patients, overall long-term results are unsatisfactory both in terms of weight loss as in terms of a high long-term complication rate. Consequently, GB should not be offered routinely to unselected morbidly obese patients. Furthermore, as no clear selection criteria has been validated yet, patients should be informed about the limitations regarding long-term weight loss and complications and other surgical options should be discussed as well.

Conflict of interest All authors declare that they have no conflict of interest in relation with this manuscript.

\section{References}

1. Belachew M, Legrand MJ, Defechereux TH, et al. Laparoscopic adjustable gastric banding in the treatment of morbid obesity. A preliminary report. Surg Endosc. 1994;8:1354-6.

2. Favretti F, Cadière GB, Segato G, et al. Laparoscopic placement of adjustable silicone gastric banding: early experience. Obes Surg. 1995;5:71-3.

3. Suter M, Giusti V, Heraief E, et al. Early results of laparoscopic gastric banding compared with open vertical banded gastroplasty. Obes Surg. 1999;9:374-80.
4. Dargent J. Laparoscopic adjustable gastric banding: lessons from the first 500 patients in a single institution. Obes Surg. 1999;9: $446-52$.

5. Suter M, Bettschart V, Giusti V, et al. A 3-year experience with laparoscopic gastric banding for obesity. Surg Endosc. 2000;14: $532-6$.

6. Zinzindohoue F, Chevallier JM, Douard P, et al. Laparoscopic gastric banding: a minimally invasive surgical treatment for morbid obesity. Prospective study of 500 consecutive patients. Ann Surg. 2003;237:1-9.

7. Ceelen W, Walder J, Cardon A, et al. Surgical treatment of severe obesity with a low-pressure adjustable gastric band. Experimental data and clinical results in 625 patients. Ann Surg. 2003;237:10-6.

8. O'Brien PE, Dixon JB, Laurie C, et al. A prospective randomized trial of placement of the laparoscopic adjustable gastric band: comparison of the perigastric and pars flaccid pathways. Obes Surg. 2005;15:820-6.

9. Suter M, Giusti V, Worreth M, et al. Laparoscopic gastric banding. A prospective, randomized study comparing the lapband and the SAGB: early results. Ann Surg. 2005;241:55-62.

10. Deitel M, Gawdat K, Melissas J. Reporting weight loss in 2007. Obes Surg. 2007;17:565-8.

11. O'Brien PE, Mac Donald L, Anderson M, et al. Long-term outcome after bariatric surgery: fifteen-year follow-up of adjustable gastric banding and a systematic review of the surgical bariatric literature. Ann Surg. 2013;257:87-94.

12. Reinhold RB. Critical analysis of long-term weight loss following gastric bypass. Surg Gynecol Obstet. 1982;1(55):385-94.

13. Higa K, Ho T, Tercero F, et al. Laparoscopic Roux-en-Y gastric bypass: 10-year follow-up. Surg Obes Related Dis. 2011;7:516-25.

14. Ardestani A, Lautz DB, Tavakkolizadeh A. Band revision versus Roux-en-Y gastric bypass conversion as salvage operation after laparoscopic adjustable gastric banding. Surg Obes Relat Dis. 2011;7:33-7.

15. Bueter M, Thalheimer A, Wierlemann A, et al. Reoperations after gastric banding: replacement or alternative procedures? Surg Endosc. 2009;23:334-40.

16. Mognol P, Chosidow D, Marmuse JP. Laparoscopic conversion of laparoscopic gastric banding to Roux-en-Y gastric bypass: a review of 70 patients. Obes Surg. 2004;14:1349-53.

17. Schouten R, Japink D, Meesters B, et al. Systematic literature review of reoperations after gastric banding: is a stepwise approach justified? Surg Obes Relat Dis. 2011;7:99-109.

18. Van Wageningen B, Berends FJ, van Ramshorst B, et al. Revision of failed laparoscopic adjustable gastric banding to Roux-en-Y gastric bypass. Obes Surg. 2006;16:137-41.

19. Weber M, Müller MK, Michel JM, et al. Laparoscopic Roux-en-Y gastric bypass, but not rebanding, should be proposed as rescue procedure for patients with failed laparoscopic gastric banding. Ann Surg. 2003;238:827-34.

20. Lanthaler M, Mittermair R, Erne B, et al. Laparoscopic gastric Rebanding versus laparoscopic gastric bypass as a rescue operation for patients with pouch dilatation. Obes Surg. 2006;16:484-7.

21. Weiss HG, Kirchmayr W, Klaus A, et al. Surgical revision after failure of laparoscopic adjustable gastric banding. Brit J Surg. 2004;91:235-41.

22. Nguyen NT, Hohmann S, Nguyen HM, et al. Outcome of laparoscopic adjustable gastric banding and prevalence of band revision and explantation at academic centers: 2007-2009. Surg Obes Relat Dis. 2012;8:724-8.

23. Weichman K, Ren C, Kurian M, et al. The effectiveness of adjustable gastric banding: a retrospective 6-year U.S. follow-up study. Surg Endosc. 2011;25:397-403.

24. Brown WA, Burton PR, Anderson M, et al. Symmetrical pouch dilatation after laparoscopic adjustable gastric banding: incidence and management. Obes Surg. 2008;18:1104-8. 
25. Himpens J, Cadière GB, Bazi M, et al. Long-term outcomes of laparoscopic adjustable gastric banding. Arch Surg. 2011;146(7): $802-7$.

26. Van Nieuwenhoge Y, Ceelen A, Stockman A, et al. Long-term results of a prospective study on laparoscopic adjustable gastric banding for morbid obesity. Obes Surg. 2011;21:582-7.

27. Lanthaler M, Aigner F, Kinzl J, et al. Long-term results and complications following adjustable gastric banding. Obes Surg. 2010;20:1078-85.

28. Suter M, Calmes JM, Paroz A, et al. A 10-year experience with laparoscopic gastric banding for morbid obesity: high long-term complication and failure rates. Obes Surg. 2006;16:829-35.

29. Balsiger BM, Ernst D, Giachino D, et al. Prospective evaluation and 7-year follow-up of Swedish adjustable gastric banding in adults with extreme obesity. J Gastrointest Surg. 2007;11:1470-7.

30. Tolonen P, Victorzon M, Mäkelä J. 11-year experience with laparoscopic adjustable gastric banding for morbid obesity - what happened to the first 123 patients? Obes Surg. 2008;18:251-5.

31. Naef M, Mouton WG, Naef U, et al. Symmetrical pouch dilatation after laparoscopic adjustable gastric banding: incidence and management. Obes Surg. 2010;20:1206-14.

32. Steffen R, Potoczna N, Bieri N, et al. Successful multiintervention treatment of severe obesity: a 7-year prospective study with $96 \%$ follow-up. Obes Surg. 2009;19:3-12.

33. Bueter M, Thalheimer A, le Roux CW, et al. Upper gastrointestinal investigations before gastric banding. Surg Endosc. 2010;24: 1025-30.

34. Klaus A, Gruber I, Wetscher G, et al. Prevalent esophageal body motility disorders underlie aggravation of GERD symptoms in morbidly obese patients following adjustable gastric banding. Arch Surg. 2006;141:247-51.
35. Klaus A, Weiss H. Is preoperative manometry in restrictive bariatric procedures necessary? Obes Surg. 2008;18:1039-42.

36. Suter M, Dorta G, Giusti V, et al. Gastric banding interferes with esophageal motility and gastroesophageal reflux. Arch Surg. 2005;140:639-43.

37. Suter M, Giusti V, Calmes JM, et al. Preoperative upper gastrointestinal testing can help predicting the long-term outcome after gastric banding for morbid obesity. Obes Surg. 2008;18:578-82.

38. Chevallier JM, Paita M, Rodde-Dunet MH, et al. Predictive factors of outcome after gastric banding. a nationwide survey on the role of center activity and patients' behavior. Ann Surg. 2007;246:1034-9.

39. Campos GM, Rabl C, Roll GR, et al. Better weight loss, resolution of diabetes, and quality of life after laparoscopic gastric bypass versus gastric banding. Results of a 2-cohort pairmatched study. Arch Surg. 2011;146:149-55.

40. Boza C, Gamboa C, Awruch D, et al. Laparoscopic Roux-en-Y gastric bypass versus laparoscopic adjustable gastric banding: five-years of follow-up. Surg Obes Relat Dis. 2010;6:470-5.

41. Tice JA, Karliner L, Walsh J, et al. Gastric banding or bypass? A systematic review comparing the two most popular bariatric procedures. Am J Med. 2008;121:885-93.

42. Nguyen NT, Slone JA, Nguyen XM, et al. A prospective randomized trial of laparoscopic gastric bypass versus laparoscopic adjustable gastric banding for the treatment of morbid obesity. Ann Surg. 2009;250:631-41.

43. Romy S, Donadini A, Giusti V, et al. Roux-en-Y gastric bypass vs gastric banding for morbid obesity. A case-matched study of 442 patients. Arch Surg. 2012;147:660-6.

44. Suter M, Calmes JM, Paroz A, et al. A new questionnaire for quick assessment of food tolerance after bariatric surgery. Obes Surg. 2007;17:2-8. 